\title{
17
}

\section{Kiski Valley WPCA Combined Sewer System Long Term Model Study}

\author{
Weizhe An and Joseph M. Gianvito
}

The Kiski Valley Water Pollution Control Authority (KVWPCA) owns and operates a combined sewer system (CSS) which includes 23 diversion chambers, eight pump stations, $12.6 \mathrm{mi}(20 \mathrm{~km})$ interceptor sewers, and a wastewater treatment plant (WWTP). KVWPCA decided to use the U. S. Environmental Protection Agency (USEPA)'s CSO Control Policy presumption approach criterion 2 through their long term control plan (LTCP) process. In order to assess the overflow volumes relative to total CSS conveyance on an annual average basis, KVWPCA completed a comprehensive flow monitoring and CSS hydrologic-hydraulic modeling study.

The RTK method was used in separate sewershed areas and a non-linear reservoir method was used in combined sewershed areas to simulate the RDII and runoff. Calibration and verification were performed using three criteria: integral square error; the percentage of model peak higher than meter peak; and the percentage of model volume higher than meter volume. To evaluate the long term system performance, a one year continuous simulation (given the typical precipitation year, which was 41.24 in., $104.74 \mathrm{~cm}$ ) was run and analyzed (USEPA, 1995b). Traditional methods for these calculations are time consuming, so the authors proposed a new method to calculate the percentage capture. The new method utilizes statistical tools, RDII, runoff, and dry weather analysis during rainfall events. It reduced the calculation time from one week to one hour. The model predicted that $88.09 \%$ combined sewage is captured and conveyed to the WWTP during wet weather in a typical precipitation year.

An, W. and J.M. Gianvito. 2011. "Kiski Valley WPCA Combined Sewer System Long Term Model Study." Journal of Water Management Modeling R241-17. doi: 10.14796/JWMM.R241-17.

(C) CHI 2011 www.chijournal.org ISSN: 2292-6062 (Formerly in Cognitive Modeling of Urban Water Systems. ISBN: 978-0-9808853-4-7) 


\subsection{Background}

KVWPCA owns and operates the CSS detailed above. Figure 17.1 illustrates the interceptor sewers, pump stations, and the WWTP. The WWTP and conveyance system are operated under NPDES permit PA0027626. (KLH Engineers, Inc., 2009)

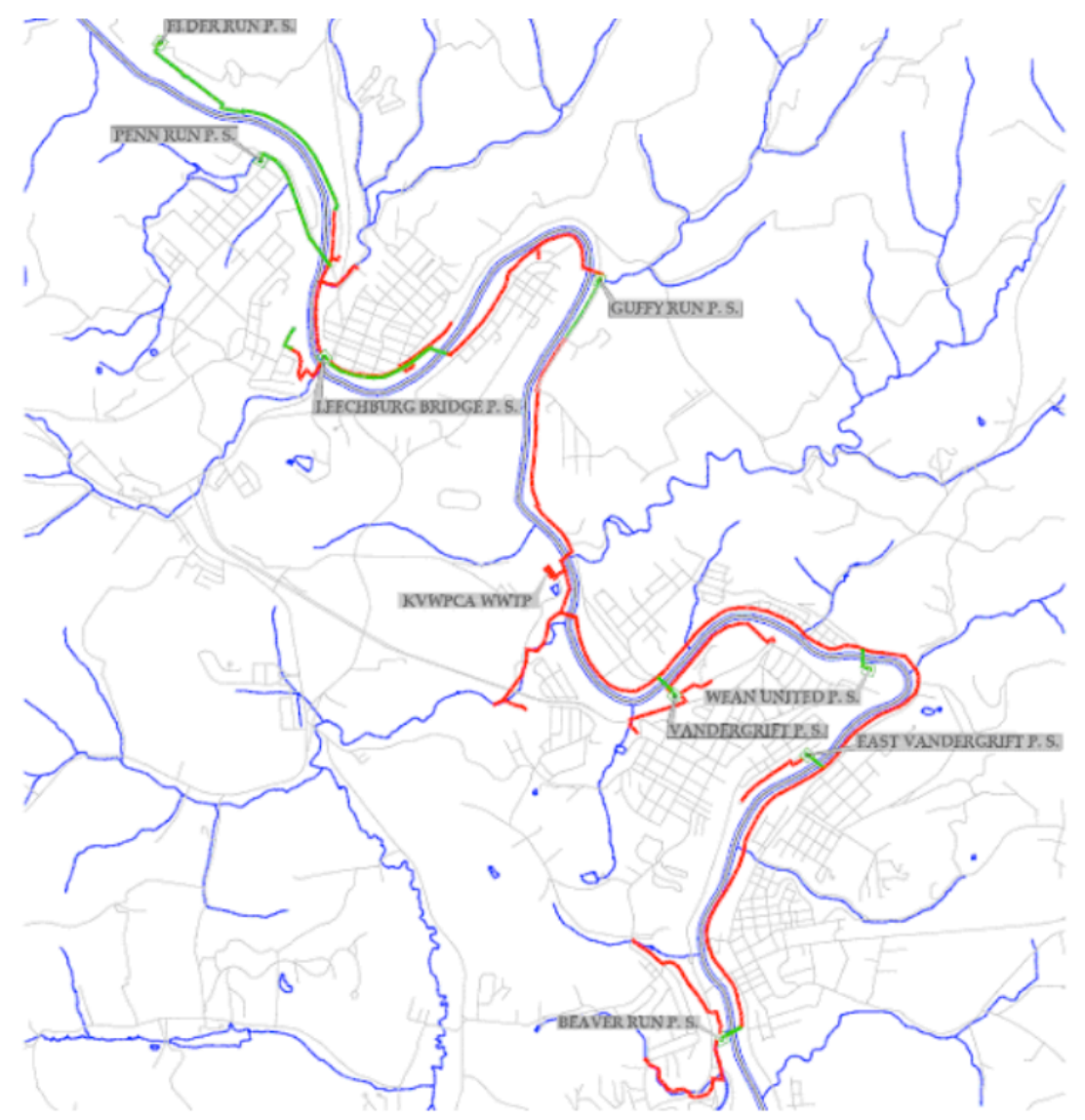

Figure 17.1 The interceptor sewers, pump stations and the WWTP.

KVWPCA provides sewage service to thirteen municipalities located in the Kiskiminetas River Valley and serves approximately 11000 customers. Tributary municipalities are located in Armstrong and Westmoreland counties as shown in Table 17.1 (KLH Engineers, Inc., 2009). 
Table 17.1 Tributary municipalities served by KVWPCA.

\begin{tabular}{ll}
\hline Armstrong County & Westmoreland County \\
Gilpin Township & Washington Township \\
Parks Township & Borough of Vandergrift \\
Kiskiminetas Township & Borough of Hyde Park \\
Borough of Leechburg & Borough of West Leechburg \\
Borough of North Apollo & Borough of East Vandergrift \\
Borough of Apollo & Borough of Oklahoma \\
& Washington Township \\
\hline
\end{tabular}

The 23 CSO outfalls are associated with five municipalities and eight pump stations and discharge into the interceptor sewer system. Interceptor sewers $12.6 \mathrm{mi}(20 \mathrm{~km})$ long were built along the Kiskiminetas River. WWTP rated flow is 7.0 MGD (306.69 L/sec). Annual average flow for 2008 was 3.703 MGD (162.24 L/sec). Complete sewer separation projects are planned for the boroughs of Apollo, East Vandergrift and Vandergrift. These projects will involve the construction of new sanitary sewer systems and conversion of the existing combined sewer systems into storm sewers.

KVWPCA decided to use the USEPA CSO control policy presumption approach criterion 2 (USEPA, 2004; USEPA, 2001) to guide their LTCP process. The criterion is:

The elimination or capture for treatment of no less than $85 \%$ by volume of combined sewage collected in the CSS during precipitation events on a system-wide annual average basis. (USEPA, 1995a)

\subsection{Flow Monitoring Study}

Flow monitoring meters were installed and maintained by Drnach Environmental, Inc. (DE). Site selection included each CSO diversion chamber, inlet flow and overflow. In total 102 flow meters were used over the duration of the study. Seven rain gauges were used for the study. Table 17.2 lists the rain gauge locations.

Table 17.2 Rain gauge locations.

\begin{tabular}{lccc}
\hline \multicolumn{1}{c}{ Rain Gauge Name } & GPS Coordinate N & GPS Coordinate W & Owner \\
\hline Penn Run & 40.642077 & 79.615395 & KVWPCA \\
Guffy & 40.633121 & 79.581607 & KVWPCA \\
Plant & 40.610181 & 79.585497 & DE \\
East Vandergrift & 40.597407 & 79.559976 & KVWPCA \\
Leechburg & 40.626825 & 79.608881 & KVWPCA \\
Vandergrift & 40.602130 & 79.573954 & KVWPCA \\
Beaver Run & 40.575189 & 79.568684 & DE \\
\hline
\end{tabular}


The flow monitoring program began on September 1, 2008 and ended on February 28, 2009. During this period five significant rain events occurred. These events are listed in Table 17.3. A significant rain event was defined as an event where rainfall depth $\geq 1$ in. $(25.4 \mathrm{~mm})$.

Table 17.3 Significant rain events during monitoring period.

\begin{tabular}{cccccc}
\hline Event No. & $\begin{array}{c}\text { Rain start date } \\
(\mathrm{M} / \mathrm{D} / \mathrm{Y})\end{array}$ & $\begin{array}{c}\text { Rain end date } \\
(\mathrm{M} / \mathrm{D} / \mathrm{Y})\end{array}$ & $\begin{array}{c}\text { Rain duration } \\
(\mathrm{h})\end{array}$ & $\begin{array}{c}\text { Rain depth } \\
\text { (in) }[\mathrm{cm}]\end{array}$ & $\begin{array}{c}\text { Average* } \\
\text { recurrence } \\
\text { interval }\end{array}$ \\
\hline 1 & $09 / 12 / 08$ & $09 / 13 / 08$ & 27 & $2.66(6.76)$ & $>2 \mathrm{yr}$ \\
2 & $10 / 24 / 08$ & $10 / 25 / 08$ & 16 & $1.02(2.59)$ & $>2 \mathrm{mo}$. \\
3 & $12 / 19 / 08$ & $12 / 19 / 08$ & 9 & $1.16(2.95)$ & $>4 \mathrm{mo}$. \\
4 & $12 / 24 / 08$ & $12 / 24 / 08$ & 21 & $1.14(2.90)$ & $>2 \mathrm{mo}$. \\
5 & $01 / 06 / 09$ & $01 / 07 / 09$ & 26 & $1.19(3.02)$ & $>2 \mathrm{mo}$. \\
\hline
\end{tabular}

*Average recurrence interval estimates from NOAA point precipitation frequency data (NOAA, 2010).

The total rainfall depth for the monitoring period was 18.18 in. (46.18 $\mathrm{cm})$. Annual average rainfall for the National Oceanic and Atmospheric Administration (NOAA) Vandergrift rain gauge is 37.63 in. $(95.58 \mathrm{~cm})$. This value is based on rainfall data recorded by NOAA from 1971 through 2000. The rainfall recorded during the monitoring period is approximately equal to the equivalent annual average rain event: 18.18 in. $/ 6$ month $(46.18 \mathrm{~cm} / 6$ months $)=36.36 \mathrm{in} . / \mathrm{y}(92.35 \mathrm{~cm} / \mathrm{y})$.

\subsection{Combined Sewer System Modeling}

\subsubsection{Model Hydrology}

There are three major components of the total sanitary sewer flow. Dry weather flow has two components: groundwater infiltration (GWI) and base wastewater flow (BWWF). The third component is rainfall dependent infiltration and inflow (RDII). For combined sewer flow, the runoff can be accounted as the fourth component, or it can be treated together with RDII as wet weather flow. GWI represents groundwater that enters the collection system through defective pipes, pipe joints, and leaking manhole walls during dry weather. BWWF is the residential, industrial and commercial flow discharged to the sewer system for collection and treatment. RDII represents the wet weather contribution that enters a separate sewer system during and after a rainfall event (USEPA. 2008). Accurate values of dry weather flow play an important role in hydrologic and hydraulic $(\mathrm{H} \& \mathrm{H})$ modeling, particularly in separate sewer systems (Non-CSOs), since the dry weather flow is a large portion of the overall flow. 
Dry weather flow loadings were determined through analysis of flow monitoring data during dry weather days, from each flow monitoring location, as well as the total system flow monitored at the WWTP. Generally, the dry weather flow varies with time of day, with two peaks at about 07:00 and 19:00, and two bottoms at about 03:00 and 15:00. In the dry weather flow analysis, multiple days of dry weather flows were collected and averaged at different times. The dry weather flows were loaded in corresponding upstream manholes. Figure 17.2 shows the typical dry weather flow pattern.

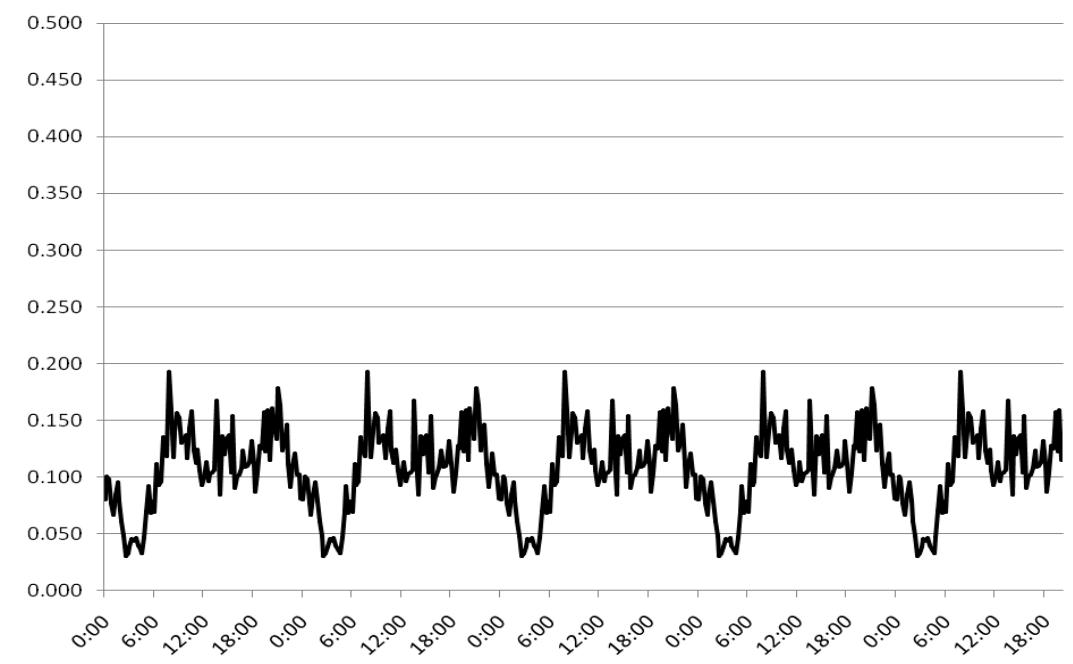

Figure 17.2 Typical dry weather flow pattern.

Wet weather flows were simulated using InfoSWMM in two ways: RTK unit hydrograph (UH) and nonlinear reservoir methods. Generally, the RTK method was used for simulating separate sewer subcatchment (non-CSOs) and the nonlinear reservoir method was used for simulating combined sewer subcatchment. In rare cases, when all parameter combinations in the nonlinear reservoir method were exhausted, but the hydrograph from combined sewer subcatchment still could not be modeled well, the RTK unit hydrograph was used in conjunction with nonlinear reservoir to better simulate the hydrograph from combined sewer subcatchment.

The amount of wet weather flow from the separate areas entering the KVWPCA conveyance system is quantified by RDII. The portion of precipitation that enters the conveyance system depends on several factors, such as the age of the system, number and severity of the defects in the system and the relative elevation of the groundwater table. The defects could be cracked 
and leaking service laterals, dilapidated manholes and improperly sealed manhole covers. The RTK method uses three triangular unit hydrographs to fit the RDII hydrograph. These three unit hydrographs represent the rapid, medium and slow sewer subcatchment responses to rainfall (USEPA, 2009) Each hydrograph is described by the following parameters as shown in Figure 17.3. The three parameters are:

$R=$ fraction of rainfall volume that enters the sewer system,

$T=$ time from the onset of rainfall to the peak of the UH in hours,

and

$K=$ ratio of time to recession of the $\mathrm{UH}$ to the time to peak.

The goal of the model calibration is to adjust the $R, T$ and $K$ parameters for each event analyzed to obtain a reasonable fit. The generally used RTK value ranges are shown in Table 17.4.

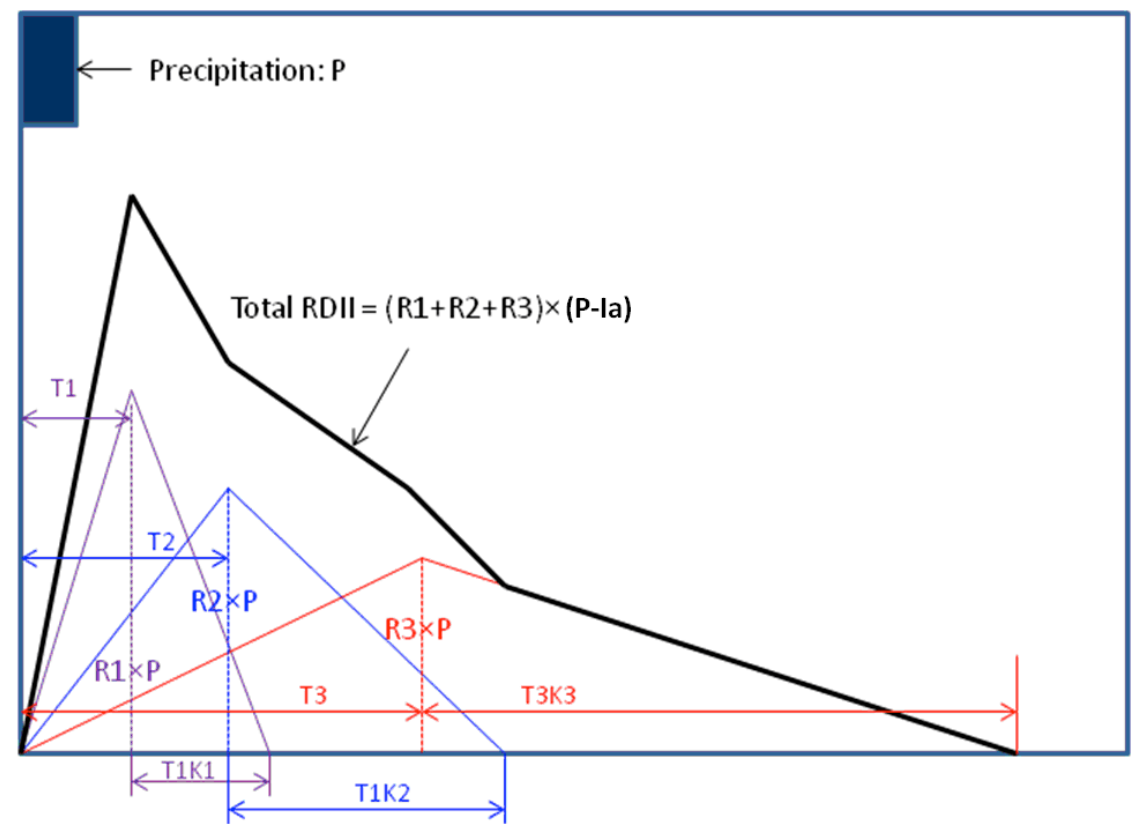

Figure 17.3 RTK method parameters used for RDII simulation (la = initial abstraction).

Table 17.4 Generally used RTK value ranges.

\begin{tabular}{ccc}
\hline Unit Hydrograph & $T$ (hour) & $K$ \\
\hline 1 & $1-2$ & $1-2$ \\
2 & $3-5$ & $2-3$ \\
2 & $5-10$ & $3-5$ \\
\hline
\end{tabular}


The primary means for storm water to enter combined sewer systems is through direct connections from roof leaders, area drains and catch basins. The hydrologic portion of SWMM is used to simulate the surface runoff from combined sewer subcatchment. This method depends on the following key parameters which together determine and represent in the model the magnitude and shape of the runoff hydrograph produced by a storm event in a combined subcatchment (MWH Soft, 2009):

Subcatchment area;

Subcatchment ground slope;

Subcatchment width;

Percentage of impervious area;

Manning's roughness for impervious area and pervious area;

Depression storage for impervious area and pervious area; and

Infiltration parameters.

The initial value of most of these parameters was estimated from the variously available GIS data, such as area, slope, and percentage of impervious area. Initial estimate of the width is given by the subcatchment area divided by the average maximum overland length. Initial Manning's roughness and depression storage were assigned to default values, which were shown in Table 17.5. Initial Horton infiltration properties were assigned based on soil type data. Horton infiltration parameters were shown in Table 17.6 for Soil Conservation Service (SCS) soil type (Chow et al., 1988; Soil Conservation Service, 1972; 1975). Although initial parameters were provided, they were adjusted to provide more realistic values. All of these refinements provide a more accurate representation of real world hydrologic processes.

Table 17.5 Default values for runoff parameters.

\begin{tabular}{lc}
\hline \multicolumn{1}{c}{ Runoff parameter } & Value \\
\hline Impervious Manning's $n$ & 0.014 \\
Pervious Manning's $n$ & 0.300 \\
Impervious storage & 0.02 in. $(0.05 \mathrm{~cm})$ \\
Pervious storage & 0.15 in. $(0.38 \mathrm{~cm})$ \\
\hline
\end{tabular}

Table 17.6 Horton infiltration parameters for SCS soil type.

\begin{tabular}{lcccc}
\hline \multicolumn{1}{c}{ SCS soil type } & A & B & C & D \\
\hline $\mathrm{F}_{0}(\mathrm{in} . / \mathrm{h})[\mathrm{cm} / \mathrm{h}]$ & $10.00(25.4)$ & $8.00(20.32)$ & $5.00(12.70)$ & $3.00(7.62)$ \\
$\mathrm{f}_{\mathrm{c}}(\mathrm{in} . / \mathrm{h})[\mathrm{cm} / \mathrm{h}]$ & $1.00(2.54)$ & $0.50(1.27)$ & $0.25(0.64)$ & $0.10(0.25)$ \\
$\mathrm{K}\left(\mathrm{h}^{-1}\right)$ & 2.00 & 2.00 & 2.00 & 2.00 \\
\hline
\end{tabular}

SWMM 5 computes the depth of water over the subcatchment continuously by solving a water balance equation over the subcatchment. 


\subsubsection{Model Hydraulics}

The purpose of a diversion chamber is to intercept and convey all of the dry weather flow, and a regulated fraction of wet weather flow, to the wastewater treatment plant. The captured (dry and wet weather) flow is conveyed by a connector pipe to the interceptor, while wet weather flow in excess of the design capacity of the regulator is diverted through a diversion weir or overflow pipe to a receiving stream. Wet wells are drainage system nodes that provide storage volume. They could represent physical storage facilities as small as a catch-basin or as large as a lake. The volumetric properties of a storage unit are described by a function or table of surface area versus height. Outfalls are terminal nodes of the drainage system which are used to define final downstream boundaries under dynamic wave flow routing or discharge overflow to the receiving stream (Huber, et al., 1988).

An orifice diversion structure is a modification of the dam structure consisting of a fixed plate or gate. At the entrance to the connector pipe, the gate or plate is designed to place additional hydraulic restrictions on flow diverted to the interceptor to that of the connector pipe. Usually the incoming municipal pipe and the overflow pipe are the same size while the connector pipe to the interceptor is smaller. As higher flows increase the hydraulic grade line (HGL) or water level in the structure, wet weather overflow in excess of the engineered conveyance capacity of the regulator device and connector pipe is diverted through an outfall pipe to a receiving stream. Pumps are links used to lift water to higher elevations. A pump curve describes the relation between a pump's flow rate and conditions at its inlet and outlet nodes (Huber et al., 1988).

The KVWPCA interceptor system is spread along the Kiskiminetas River. The system consists of a north section and a south section, with the treatment plant in the middle. Eight pump stations are used to lift water when the upstream node is lower than downstream node. Example profiles of the interceptor are shown in Figure 17.4 and Figure 17.5.

Hydraulic routing of dry and wet weather flows was accomplished using dynamic wave flow routing. Although analysis when using this method is complex and time consuming, it is well suited to CSSs which are subject to a variety of hydraulic conditions. 


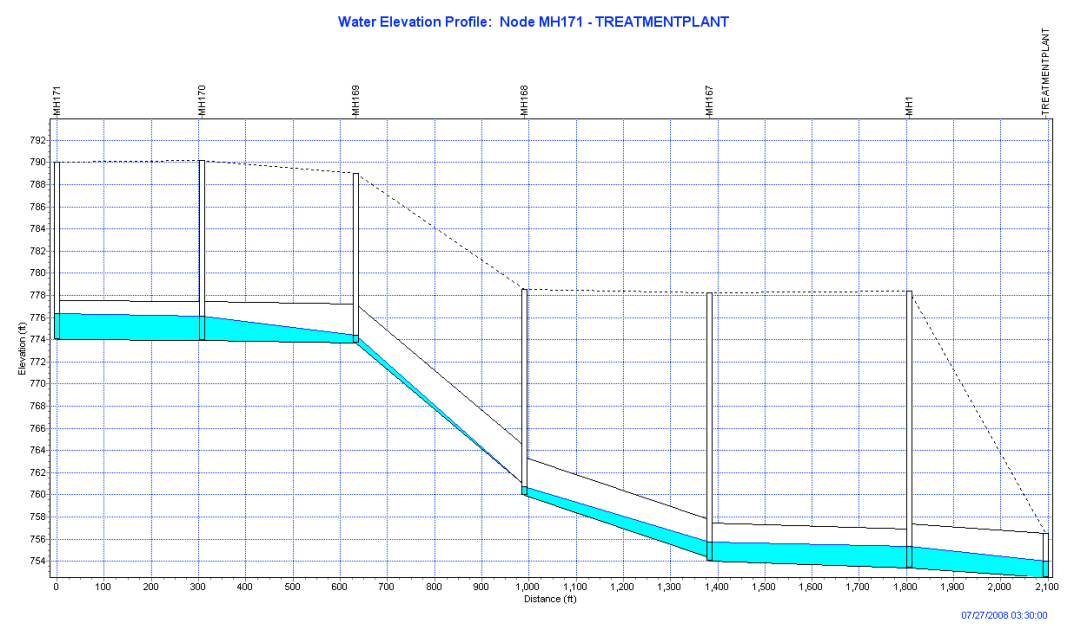

Figure 17.4 Interceptor profile between manhole $\mathrm{MH} 171$ and outfall treatment plant.

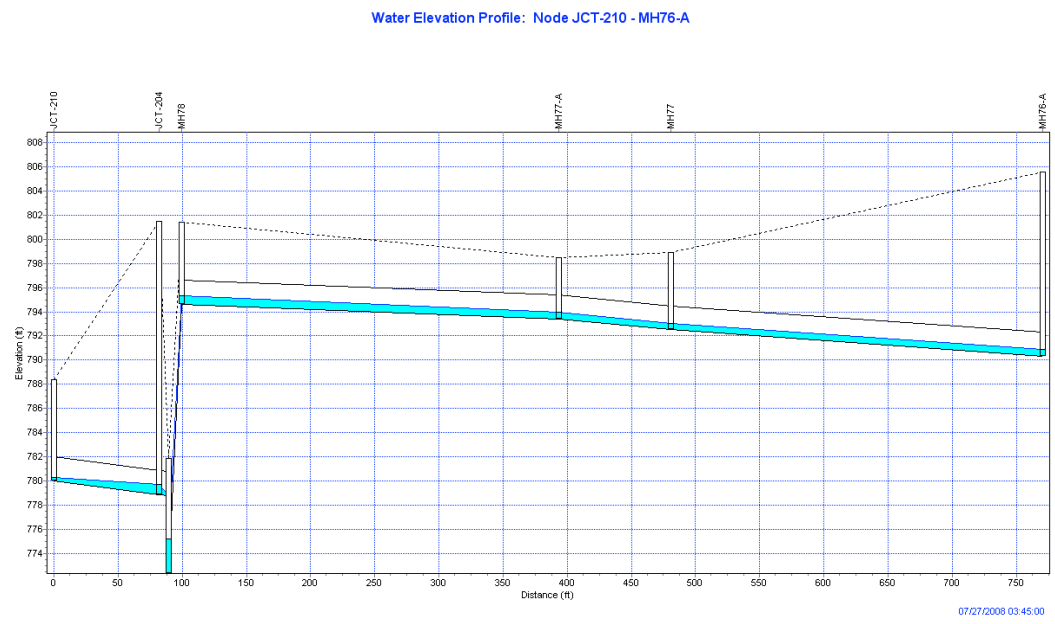

Figure 17.5 Interceptor profile between manholes JCT210 and MH76A (including a pump station).

\subsubsection{Model Calibration and Verification}

\section{Model Development}

The major characteristics of interceptors in the model, which include conduit length, size, manhole invert and manhole depth, were developed using rec- 
ord drawings. The record drawings, which were provided by KVWPCA, include interceptor characteristics in all municipalities except Washington Township.

Unlike subcatchment hydrological parameters, the major characteristics of interceptors were deemed to be fixed and were not adjusted during the model calibration process, unless reliable investigation showed that there was an update for a manhole or conduit.

The characteristics of pump stations were derived from two main sources. First was the record drawings for wastewater pumping facilities, provided by KVWPCA; second was the pump station flow meter data from KVWPCA. Based on these, the pump curves were developed and integrated in the model.

The characteristics of wet wells were derived from the record drawings, from which the wet well depth-volume curves were developed and integrated in the model. Additionally field data collected by Drnach Environmental (manhole inspection with site photographs, precipitation data, and flow monitoring data) were used.

The KVWPCA model was used as a predictive tool to characterize the wastewater collection system in the Kiski Valley Basin under existing and future conditions. To calibrate the KVWPCA model, extensive basin wide flow monitoring was conducted to collect the required data. This data, after being subjected to quality assurance procedures, was compared to the model results at the monitored locations. The model input parameters were then subject to calibration to facilitate a closer correlation between the observed data and the simulated results.

\section{Calibration and Verification Criteria}

The accuracy of the developed model during wet weather events is essential for evaluation of the percentage capture and conveyance criteria. To make sure that the model accurately represents the best available information, a rigorous program of wet weather calibration was applied to the KVWPCA model using a large quantity of quality-assured monitoring data. Hydrologic calibration was conducted for all of the monitored sites to properly simulate the wet weather response from the monitored subcatchment. Hydrologic calibration of a monitored subcatchment was an event based exercise.

Calibration was evaluated in terms of three criteria: integral square error (ISE), the percentage of model peak higher than meter peak $\left(P_{p e r}\right)$, and the percentage of model volume higher than meter volume $\left(V_{p e r}\right)$. These criteria were used in conjunction when determining whether or not a particular portion of the system was adequately calibrated. Flow monitoring points with missing, errant or unreasonable responses were identified and classified as 
outlier points. These outliers were removed or interpolated using nearby data, so they did not unduly affect the results of the analysis. If the flow monitoring contains missing, errant or unreasonable data for a long time period for a specific sewer subcatchment, a different rainfall event was employed in the calibration or verification event for this subcatchment. The iterative process of optimizing the runoff and RDII parameters was continued until the calibration objectives were achieved. The definitions of ISE, $P_{p e r}$ and $V_{p e r}$ are shown in Equation 17.1, Equation 17.2 and Equation 17.3.

$$
\begin{aligned}
& I S E=\frac{\left[\sum_{i=1}^{N}\left(O_{i}-M_{i}\right)^{2}\right]^{1 / 2}}{\sum_{i=1}^{N} M_{i}} \times 100 \% \\
& P_{p e r}=\frac{P_{o}-P_{m}}{P_{o}} \times 100 \% \\
& V_{p e r}=\frac{V_{o}-V_{m}}{V_{o}} \times 100 \%
\end{aligned}
$$

where:

$O_{i}=$ observed hydrograph value at time $i$,

$M_{i}=$ modeled hydrograph value at time $i$,

$N=$ number of hydrograph values,

$P_{o}=$ observed hydrograph peak,

$P_{m}=$ modeled hydrograph peak,

$V_{o}=$ observed hydrograph total volume, and

$V_{m}=$ modeled hydrograph total volume.

The purpose of the calibration process for monitored combined and separate subcatchments is to determine the runoff parameters and RDII parameters to achieve the following goals of model calibration. Generally speaking, peaks and volumes within $10 \%$ are considered to be well calibrated and $I S E \leq 10$ indicates a reasonable goodness of fit.

It is important to emphasize that with complex physical conditions and variation in flow monitoring, large $I S E, P_{\text {per }}$ and $V_{\text {per }}$ are expected and acceptable in the calibration process, especially for overflow calibration, as long as there is no overall bias demonstrated in the average comparison. With the long term continuous simulation modeling approach that was adopted for the KVWPCA CSS, simulation of individual storms is not significant when compared with the accuracy of the overall model simulation over the course of the total model duration. The criterion is to make sure that 
there is no overall bias in the simulations, and that over-simulation and under-simulation of individual storms balance out over the course of the long term simulation.

\section{Model Calibration}

Once the model was built it was calibrated using flow data from each meter location. The model was calibrated to the September 12-13 2008 rain event, which has total rainfall depth of $2.66 \mathrm{in} .(6.76 \mathrm{~cm})$ and is slightly larger than a 2 y storm. This rain event was selected because the antecedent conditions appeared to be approximately average during this time period.

For sanitary flow portions, calibration was completed where the RTK method was used by modifying the hydrograph parameters, where $R$ is the fraction of rainfall entering the system, $T$ is the time to peak, and $K$ is the ratio of recession time to the time to peak. Care must be taken because although the RTK method can model various hydrographs, their values cannot be adjusted arbitrarily. The guideline in Section 17.3.1 was followed in most cases.

For combined flow portions, calibration was completed where the nonlinear reservoir method was used by modifying hydrologic parameters within a reasonable range. These adjustable parameters are subcatchment area, subcatchment width, subcatchment slope, percentage of impervious area, Manning's $n$ for impervious area, Manning's $n$ for pervious area, depression storage for impervious area, depression storage for pervious area, percentage of impervious area with no depression storage, and the Horton infiltration parameters. It should be emphasized that although the subcatchment area should be determined from GIS data and be fixed, it is very difficult to obtain an accurate tributary area. Thus it is allowable to adjust the area within small range. Other parameters should be refined within reasonable ranges based on guidelines in Section 17.3.1.

Given use of the CSS $85 \%$ capture for the presumption approach, how closely the model CSO volume matched the metered CSO volume was considered to be most critical. A comparison of total CSO volume generated by the model versus total metered CSO volume for the September 12-13 rain event showed that the model resulted in a total volume that was $50.52 \%$ higher than the metered total volume. The model resulted in a total peak that was $3.95 \%$ higher than the metered total peak. It should be noted that the modeling of the overflow is extremely difficult because the overflow duration is short and the overflow amount is small compared to the inflow. A small amount of difference in modeling will generate a big percentage difference. 
Other modeling results in calibration are volumes and peaks for non-CSO inflows, CSO inflows, and combinations of the two. As stated in Section 17.2, a total of 102 flow meters and seven rain gauges were used through the duration of the study. Due to space limitations, it is impossible to list all the modeling results. Table 17.7 shows the summary of modeling and monitoring volumes and peaks in model calibration.

Table 17.7 The comparison summary of modeling and monitoring volumes and peaks in calibration.

\begin{tabular}{|c|c|c|c|c|c|c|c|}
\hline Calibration & $\begin{array}{c}\text { Total } \\
\text { meter } \\
\text { volume } \\
(\mathrm{MG})\end{array}$ & $\begin{array}{c}\text { Total } \\
\text { model } \\
\text { volume } \\
(\mathrm{MG})\end{array}$ & $\begin{array}{c}\text { Total } \\
\text { meter } \\
\text { peak } \\
\text { (MGD) }\end{array}$ & $\begin{array}{c}\text { Total } \\
\text { model } \\
\text { peak } \\
\text { (MGD) }\end{array}$ & $\begin{array}{l}\text { Average } \\
\text { ISE }\end{array}$ & $\begin{array}{c}\text { Model } \\
\text { volume-- } \\
\text { meter } \\
\text { volume (\% } \\
\text { high) }\end{array}$ & $\begin{array}{c}\text { Model } \\
\text { peak- } \\
\text { meter } \\
\text { peak } \\
(\% \text { High })\end{array}$ \\
\hline Non-CSOs (1) & 8.23 & 8.33 & 22.55 & 22.91 & 8.94 & 1.18 & 1.61 \\
\hline CSOs (2) & 20.01 & 20.94 & 120.89 & 127.04 & 14.78 & 4.63 & 5.08 \\
\hline Overflows (3) & 4.96 & 7.47 & 77.02 & 80.06 & 44.04 & 50.52 & 3.95 \\
\hline $\begin{array}{l}\text { Non-CSOs + } \\
\text { CSOs }(1+2)\end{array}$ & 28.24 & 29.27 & 143.44 & 149.95 & 11.27 & 3.62 & 4.54 \\
\hline $\begin{array}{l}\text { CSOs+Overflow } \\
\mathrm{s}(2+3)\end{array}$ & 24.97 & 28.41 & 197.91 & 207.10 & 29.73 & 13.74 & 4.64 \\
\hline Total $(1+2+3)$ & 33.20 & 36.73 & 220.46 & 230.01 & 20.94 & 10.63 & 4.33 \\
\hline
\end{tabular}

\section{Model Verification}

In order to confirm that the calibrated model could be reasonably applied to other rain events in different hydrologic conditions, the model was verified. Verification was completed using rainfall that occurred on December 24-25, 2008 which had a depth of 1.02 in. $(2.59 \mathrm{~cm})$ and is slightly larger than a 2 month storm. The verification process was performed using exactly the same parameters, which were obtained from the calibration process.

A comparison of total CSO volume generated by the model volume versus total metered CSO volume for the October 24-25 rain event showed that the model resulted in a total volume that was $1.52 \%$ lower than the metered total volume. The model resulted in a total peak that was $29.17 \%$ lower than the metered total peak. This indicates that the model was slightly underpredicting overflow volumes, given the December 24-25 hydrologic conditions. Calibration and verification indicate that the model is conservative in terms of KVWPCA CSS meeting the presumption approach.

Other modeling results in verification are volumes and peaks for nonCSO inflows, CSO inflows, and combination of them. Due to space limitations, it is impossible to list all modeling results. Table 17.8 shows the comparison of modeling and monitoring volumes and peaks in model verification. 
Table 17.8 The comparison summary of modeling and monitoring volumes and peaks in verification.

\begin{tabular}{lccccccc}
\hline \multicolumn{1}{c}{ Calibration } & $\begin{array}{c}\text { Total } \\
\text { meter } \\
\text { volume } \\
(\mathrm{MG})\end{array}$ & $\begin{array}{c}\text { Total } \\
\text { model } \\
\text { volume } \\
(\mathrm{MG})\end{array}$ & $\begin{array}{c}\text { Total } \\
\text { meter } \\
\text { peak } \\
(\mathrm{MGD})\end{array}$ & $\begin{array}{c}\text { Total } \\
\text { model } \\
\text { peak } \\
(\mathrm{MGD})\end{array}$ & $\begin{array}{c}\text { Average } \\
\text { ISE }\end{array}$ & $\begin{array}{c}\text { Model } \\
\text { volume- } \\
\text { meter } \\
\text { volume }(\% \\
\text { high) }\end{array}$ & $\begin{array}{c}\text { Model } \\
\text { peak- } \\
\text { meter } \\
\text { volume } \\
(\% \text { high })\end{array}$ \\
\hline $\begin{array}{l}\text { Non-CSOs (1) } \\
\text { CSOs (2) }\end{array}$ & 4.23 & 4.49 & 7.09 & 7.09 & 5.82 & 6.07 & 0.03 \\
$\begin{array}{l}\text { Overflows (3) } \\
\text { Non-CSOs + }\end{array}$ & 1.40 & 8.90 & 37.22 & 24.82 & 9.52 & -3.09 & -33.31 \\
$\begin{array}{l}\text { CSOs (1+2) } \\
\text { CSOs+Overflows }\end{array}$ & 13.41 & 13.39 & 12.69 & 8.99 & 56.01 & -1.52 & -29.17 \\
$(2+3)$ & 10.57 & 10.27 & 49.31 & 31.92 & 7.30 & -0.20 & -27.97 \\
\hline Total $(1+2+3)$ & 14.81 & 14.76 & 57.00 & 40.91 & 17.74 & -0.32 & -28.24 \\
\hline
\end{tabular}

Overall the model is considered to be well calibrated and well suited to the evaluation of system performance relative to varying rain events.

\subsection{Long term Continuous Simulation}

In order to determine whether or not the KVWPCA CSS meets the chosen criterion, criterion 2, it was necessary to determine the annual average rainfall. Data available from the KVWPCA was not considered to be for a long enough time period to determine historical annual average rainfall. Therefore a NOAA database search was performed.

The NOAA gauged site closest to KVWPCA was Vandergrift. However, NOAA only has monthly rainfall and daily normals for this site. No $15 \mathrm{~min}$ interval rainfall data is available. Daily normals at Vandergrift from 1971 through 2000 were downloaded. Based on this data, the annual average rainfall depth at KVWPCA (Vandergrift) was determined to be 37.63 in. (95.58 $\mathrm{cm})$. The KVWPCA rain data was not available; therefore Greensburg 15 min interval rainfall data was used (the Greensburg rain gauge site is 20 mi south of KVWPCA). This data was used because it was readily available and it is representative of the annual average conditions for the Kiskiminetas River Valley. This rainfall, which occurred between October 1, 2007 and September 30, 2008 was 41.24 in. (104.75 cm). Use of this higher rainfall provides an additional factor of safety.

Defining wet weather flow for the evaluation of percentage capture can be difficult due to the fact that it is somewhat arbitrary as to when the wet weather flow should end and thus the total volume be determined. The longer the recession period included in the calculation, the more favorable the comparison of captured flow volume to overflow volume will be. Traditional methods for these calculations involve computing wet weather flow and dry weather flow during wet weather period for each rain events in the whole 
year. This normally takes one week or even longer depending on the size of system.

After careful review with the monitoring flow and modeled flow in the WWTP, the maximum total dry weather flow is found to be 2.75 MGD $(120.48 \mathrm{~L} / \mathrm{sec})$. Since the $2.75 \mathrm{MGD}(120.48 \mathrm{~L} / \mathrm{sec})$ is the maximum total dry weather flow, any flow over 2.75 MGD $(120.48 \mathrm{~L} / \mathrm{sec})$ must be wet weather flow. Equation 17.4 was used for percent capture evaluation.

$$
\% \text { Capture }=100 \times V_{\text {WWTPWW }} /\left(V_{\text {DWFWW }}+V_{R D I I}+V_{R U N O F F}\right)
$$

where:

$V_{\text {WWTPWW }}=$ total volume of flow conveyed to the WWTP during wet weather time,

$V_{D W F W W}=$ total volume of dry weather flow conveyed to the WWTP during wet weather time,

$V_{R D I I}=$ total volume of rainfall dependent inflow and infiltration, and

$V_{\text {RUNOFF }}=$ total volume of runoff (includes overflows).

Using 2.75 MGD $(120.48 \mathrm{~L} / \mathrm{sec})$ as wet weather flow threshold and $6 \mathrm{~h}$ as the inter-event threshold time, the total wet weather duration and total inflow to the WWTP during wet weather $\left(V_{\text {WWTPWW }}\right)$ can be calculated. $V_{D W F W W}$ can be calculated by multiplying $2.75 \mathrm{MGD}(120.48 \mathrm{~L} / \mathrm{sec})$ by the total wet weather duration. This new calculation method reduced the calculation time from one week (traditional methods) to one hour. These volumes were determined based on the one year simulation.

$$
\begin{aligned}
V_{W W T P W W} & =627.28 \mathrm{MG}\left(237.45 \times 10^{4} \mathrm{~m}^{3}\right) \\
V_{D W F W W} & =291.21 \mathrm{MG}\left(110.23 \times 10^{4} \mathrm{~m}^{3}\right) \\
V_{R D I I} & =122.94 \mathrm{MG}\left(46.54 \times 10^{4} \mathrm{~m}^{3}\right) \\
V_{R U N O F F} & =297.94 \mathrm{MG}\left(112.78 \times 10^{4} \mathrm{~m}^{3}\right) \\
\% \text { Capture } & =100 \times 627.28 /(291.21+122.94+297.94)=88.09 .
\end{aligned}
$$

Based on this one mean year simulation modeling, the KVWPCA CSS, on a system-wide annual average basis, meets the presumption approach criterion 2.

\subsection{Conclusions}

According to USEPA's regulations, KVWPCA has selected to use the EPA CSO control policy presumption approach criterion 2 in their LTCP process. In order to assess the overflow volumes relative to total CSS conveyance on an annual average basis, KVWPCA completed a comprehensive flow monitoring and CSS hydrologic-hydraulic modeling study. 
On the basis of our analysis of flow monitoring data as well as the SWMM model, it is evident that the KVWPCA conveyance system meets the USEPA CSO control policy presumption approach criterion 2, based on existing system flows and conditions. The CSS is capable of capturing and conveying flows $>85 \%$ on a system wide annual average basis.

Sewer separation projects are planned for the boroughs of Apollo, East Vandergrift and Vandergrift (KLH Engineers, Inc., 2009); thus in the near future, percentage capture should significantly increase.

\section{References}

Chow, V. T., Maidment, D. R., and Mays, L. W. (1988). Applied hydrology, McGrawHill Book Company, New York.

Huber, W.C. and R. E. Dickinson. (1988). Storm Water Management Model - Version 4: User's Manual; Cooperative Agreement CR-811607; U.S. EPA; Athens, Georgia.

KLH Engineers, Inc. (2009). Kiski Valley Water Pollution Control Authority Combined Sewer System Flow Monitoring and Modeling Study.

MWH Soft. (2009). InfoSWMM Users Guide.

NOAA. (2010) http://hdsc.nws.noaa.gov/hdsc/pfds/orb/pa_pfds.html

Soil Conservation Service. (1972). National Engineering Handbook, section 4, Hydrology, U. S. Dept of Agriculture, Washington, DC.

Soil Conservation Service. (1975). Urban hydrology for small watersheds, tech. rel. no. 55, U.S. Dept of Agriculture, Washington, DC.

USEPA. (1995a). Combined Sewer Overflows - Guidance for Long Term Control Plan. USEPA. (1995b). Combined Sewer Overflows - Guidance for Monitoring and Modeling. USEPA. (2001). Report to Congress - Implementation and Enforcement of the Combined Sewer Overflow Control Policy.

USEPA. (2004). Report to Congress - Impacts and Control of CSOs and SSOs.

USEPA. (2008). Review of Sewer Design Criteria and RDII Prediction Methods.

USEPA. (2009). SWMM 5 Users Manual. 